\title{
Mujeres, Derechos y Equidad
}

\section{Women, Rights and Equity}

\author{
Marta Sahagún-Navarro \\ Editora en Jefe \\ Corporación Universitaria del Caribe CECAR. Facultad de Humanidades y Educación. \\ $\triangle$ revistabusqueda@cecar.edu.co \\ https://orcid.org/0000-0002-6439-0672 \\ Yuly-Marcela Parra-Montoya \\ Editora Asociada \\ Corporación Universitaria del Caribe CECAR. Facultad de Humanidades y Educación, \\ $\triangle$ revistabusqueda@cecar.edu.co \\ https://orcid.org/0000-0002-3855-9382 \\ Lisbeth-Margarita Hoyos-Córdoba \\ Editora Asociada \\ Corporación Universitaria del Caribe CECAR. Facultad de Humanidades y Educación, \\ $\triangle$ revistabusqueda@cecar.edu.co \\ https://orcid.org/0000-0002-0784-6039
}

Históricamente, las mujeres en el mundo han logrado realizar un proceso de construcción colectiva que ha visibilizado temas que hoy son objeto de política pública como la participación en espacios de decisión política, la violencia sexual, intrafamiliar y las violencias ocultas, a su vez, la vida sexual y reproductiva. Sin duda, las diversas organizaciones han permitido dar un alcance mayor que ha ampliado el espectro y la mirada a los derechos y a la equidad de las mujeres.

La preocupación por los derechos de las mujeres se empieza a evidenciar ya hace más de seis décadas con el Pacto Internacional de los Derechos Civiles y Políticos y el Pacto Internacional de Derechos Económicos, Sociales y Culturales aprobado en 1966. Este último instó a los Estados a la adopción de medidas necesarias para asegurar igual título de goce de todos los derechos a hombres y mujeres, haciendo énfasis en que la discriminación contra la mujer estaba constituida por toda distinción, exclusión o restricción basada en el sexo que tenga por objeto o por resultado el no reconocimiento, la limitación o la amenaza del ejercicio de sus derechos. Sin embargo, aún el marco normativo y de actuación, continúa siendo insuficiente y las cifras de violencia siguen en aumento.

Según los datos de la Organización de las Naciones Unidas (ONU, 2018):

El 35\% de las mujeres de todo el mundo ha sufrido violencia física o sexual por parte de un compañero sentimental, o violencia sexual por parte de otra persona distinta a su compañero sentimental [...] el 70\% de las mujeres ha experimentado violencia física o sexual por parte de un compañero sentimental durante su vida" (sección Diferentes formas de violencia, párr. 1). 
Se destaca el número de mujeres asesinadas por violencia de género en todo el mundo, la cual asciende a 87.000 mujeres muertas, de las cuales el 58\% (unas 50.000) fueron asesinadas por sus parejas o miembros familiares (ONU, 2018). La violencia contra las mujeres representa la violación más generalizada de los derechos humanos, siendo el feminicidio su máxima expresión y Latinoamérica, la región que registra tasas más altas (Guajardo y Cenitagoya, 2017). Concretamente, en Colombia, han sido asesinadas 1.116 mujeres en contextos de violencia intrafamiliar, violencia sexual y violencia de pareja (Lodoño, Rubio y Castro, 2017).

La normalización de la violencia contra la mujer se determina como uno de los factores de riesgo más relevantes (Suárez-Sierra, 2018). Se destaca la necesidad de abordar esta problemática desde su prevención. En este sentido, las herramientas TIC han ido cobrando mayor relevancia para la prevención de feminicidios mediante botones de pánico, como es el caso de AsT y Viomapp, pues en un $48 \%$ de los casos registrados los delincuentes violentos se encontraban ausentes al llegar la policía. No obstante, estas soluciones TIC no han sido de carácter anticipatorio, de manera que considere "aspectos como tendencias relacionadas a la agresión, gestión por niveles de riesgo y apoyo interinstitucional que permitan dar una solución integral, a la vez que prevenir y atacar los casos de emergencia, apoyándose en la institucionalidad presente en el territorio" (Vidal et ál., 2018, p. 279). De lo anterior, estos autores señalan una propuesta para aplicativos móvil denominado Voice app, el cual fue diseñado como una estrategia integral en la gestión contra la violencia de género.

En este número 23, la revista "Búsqueda" adopta la estrategia de editar un número monográfico sobre Mujeres, Derechos y Equidad, que visiona distintos estudios realizados en el campo de la investigación científica y feminista, así como artículos misceláneos que le apuntan a otras áreas del conocimiento. En los últimos años, la revista Búsqueda se ha ido posicionando en un referente de difusión del conocimiento científico en ciencias sociales y afines, a través de la publicación de artículos originales e inéditos, revisados por pares externos con una reconocida trayectoria académica e investigativa. En este nuevo número, seguimos perfeccionado algunos aspectos editoriales, en sintonía con los estándares y criterios nacionales e internacionales sobre publicaciones científicas, con el objetivo de tener mayor visibilidad e impacto. Se reitera el agradecimiento a quienes han colaborado en el crecimiento y mayor proyección de la revista y se invita a la comunidad científica a someter sus artículos científicos para su potencial publicación.

\section{REFERENCIAS}

Guajardo, G., Cenitagoya, V. (Eds.) (2017). Femicidio y suicidio de mujeres por razones de género. Desafíos y aprendizajes en la Cooperación Sur-Sur en América Latina y el Caribe. FLACSO-Chile.

Londoño Toro, B., Rubio, L.O., Castro, J.F. (2017). La violencia de género no tiene fronteras. Estudio comparativo de las normativas colombiana y española en materia de violencia de género (2004-2014). Derecho del Estado no 38, Universidad Externado de Colombia, pp. 127-154. https://doi.org/10.18601/01229893.n38.05 
ONU (2018). Hechos y cifras: Acabar con la violencia contra mujeres y niñas. ONU mujeres. $\quad$ https://www.unwomen.org/es/what-we-do/ending-violence-againstwomen/facts-and-figures

Suárez-Sierra, M.T. (2018). Factores de riesgo en la violencia contra la mujer en el municipio de Ventaquemada (Boyacá) desde una mirada de trabajo social. Búsqueda, 5(20), 63-74. https://doi.org/10.21892/01239813.392

Vidal, J.V., Sahagún, M., Bertel, E.A., Sierra, M.J., Tapia, V.D.J. (2018). VoiceApp: una innovación tecnológica para la gestión contra la violencia de género. En M. Sahagún; J. Arias (Comp.), Violencia de género desde un abordaje interdisciplinar (pp. 275297). Universidad Sergio Arboleda. https://doi.org/10.21892/9789585511453 